\title{
Reexpansion of Collapsed Li-Montmorillonites; Evidence on the Location of $\mathrm{Li}^{+}$ions José M. Trillo,* María D. Alba, Rafael Alvero and Miguel A. Castro \\ Departamento de Química Inorgánica. Instituto de Ciencia de Materiales, Universidad de Sevilla-Consejo Superior de Investigaciones Científicas, PO Box 874, Sevilla, Spain
}

Reexpansion of Li-montmorillonites previously collapsed at $300^{\circ} \mathrm{C}$ has been attained under high vapour water pressures, and direct experimental evidence on the location of $\mathrm{Li}^{+}$ions in the hexagonal holes of the collapsed structure is provided.

Knowledge of the interaction mechanisms after thermal and hydrothermal treatments between the smectite lattice and the cations present in its interlayer space is important for the design of new materials, such as radionuclide waste repository components and solid-acid catalysts. ${ }^{1}$

Classical studies ${ }^{2}$ showed that lithium-saturated dioctahedral montmorillonites irreversibly lose their expandable character and hydration capacity, and exhibit greatly reduced exchange capacities, following heat treatment at $200-300^{\circ} \mathrm{C}$. Subsequently, a great deal of work has been done on this subject, known as the Hofmann-Klemen effect, using various techniques, and there have been different opinions regarding the reaction mechanism. Some workers have suggested that lithium ions migrate from the interlayer positions to the vacant octahedral sites on the basis of IR studies ${ }^{3}$ and after observing that montmorillonite is the only mineral of the group which has been found to show this effect when saturated with $\mathrm{Li}^{1}{ }^{4}$ On the other hand, the lack of increase in the $b$-axis dimension of heat-treated clays, along with some IR measurements supports a hypothesis based on the migration of suitable cations into the hexagonal oxygen network. ${ }^{5}$ Alternative mechanisms, such as entrapment of $\mathrm{Li}^{\mathrm{I}}$ in collapsed interlayers 


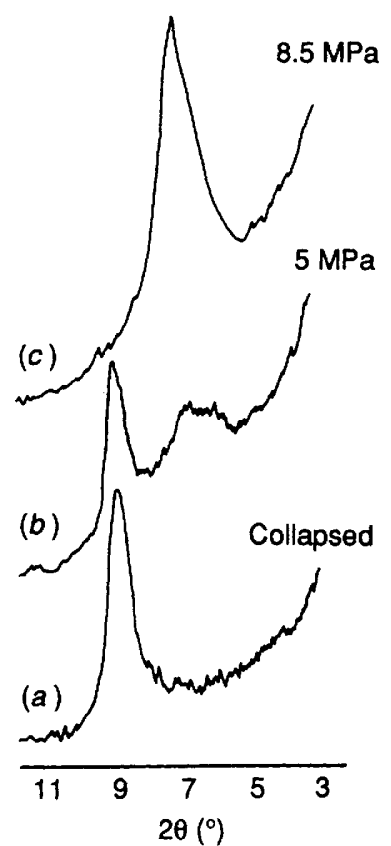

Fig. 1 XRD patterns of the Wyoming SWy-1 Li-montmorillonite: $(a)$ treated at $300^{\circ} \mathrm{C}$ during $24 \mathrm{~h}$ in air; (b) and (c) samples (a) after heating at $300^{\circ} \mathrm{C}(24 \mathrm{~h})$ under the water vapour pressures indicated

and hydrolysis, have also been proposed, 6 although they cannot be interpreted as those finally responsible for the effect.

Despite widespread use of the Hofmann-Klemen effect in mineralogical investigations, there is still controversy. ${ }^{7}$ Thus, in a recent MAS NMR study, Luca et al. ${ }^{7 a}$ interpreted the non-variation of the $\mathrm{AI}{ }^{\mathrm{VI}}$ signal as indirect evidence of non-migration of $\mathrm{Li}^{+}$ions to the octahedral layer, contrary to the conclusion of Williams et al. ${ }^{7 b}$ However, the ${ }^{27} \mathrm{Al}$ MAS NMR results reported by $\mathrm{Luca}^{7 a}$ are obtained for a sample essentially without $\mathrm{Al}^{\mathrm{IV}}$ isomorphous substitutions, and could not directly reveal structural changes occurring in the tetrahedral layer.

In the present work, unexpected reexpansion of collapsed Li-montmorillonites is reported, using two different samples with different charge-deficit distributions. Additional ${ }^{27} \mathrm{Al}$ and ${ }^{29} \mathrm{Si}$ MAS NMR measurements of the initial, collapsed, and reexpanded $\mathrm{Li}$-saturated smectites provide direct evidence on the reaction mechanism.

The two montmorillonites selected were a Wyoming sample, designated $S W y-1$, with a charge deficit per unit cell of 0.68 corresponding predominantly to isomorphous substitutions in the octahedral sheet, 8 and a Trancos sample from Gador (Spain) with a charge deficit value of 0.87 distributed as 0.36 and 0.51 between tetrahedral and octahedral layers. ${ }^{9}$ This charge-deficit distribution along with the Greene-Kelly test result ${ }^{1 b}$ permits consideration of this sample to be within the montmorillonite group.

Reexpansion experiments of collapsed samples, monitored by means of X-ray powder diffraction, were carried out by heating at $300^{\circ} \mathrm{C}$ during $24 \mathrm{~h}$ under water vapour atmospheres at different pressures. Fig. 1 includes the $d(001)$ signals corresponding to the collapsed Wyoming sample, as well as those treated at 5 and $8.5 \mathrm{MPa}$. The sample treated at the higher pressure shows a basal spacing of $11.9 \AA$, a typical value for a non-collapsed lithium-saturated montmorillonite with the $\mathrm{Li}$ ions located in the interlamellar space, whereas the 5 $\mathrm{MPa}$-treated one presents a $d(001)$ reflexion corresponding to $9.6 \AA$ along with a broad band at higher spacing. Similar results were obtained for the other sample studied, which has a greater tetrahedral charge deficit. The montmorillonite

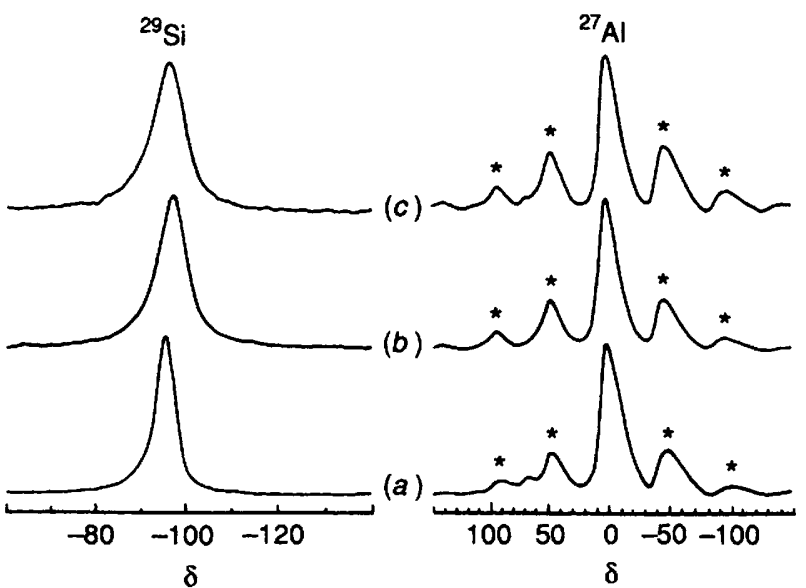

Fig. $2{ }^{29} \mathrm{Si}(59.60 \mathrm{MHz})$ and ${ }^{27} \mathrm{Al}(78.23 \mathrm{MHz})$ MAS NMR spectra of the Trancos Li-montmorillonite: $(a)$ non-treatred $\left(25^{\circ} \mathrm{C}\right) ;(b)$ treated at $300^{\circ} \mathrm{C}$ during $24 \mathrm{~h}$ in air; (c) reexpanded at $300^{\circ} \mathrm{C}$ during $24 \mathrm{~h}$ under an atmosphere of water vapour at $8.5 \mathrm{MPa}$. The ${ }^{29} \mathrm{Si}$ and ${ }^{27} \mathrm{Al} \mathrm{MAS}$ NMR chemical shifts are relative to $\mathrm{SiMe}_{4}$ and $\mathrm{AlCl}_{3} \cdot 6 \mathrm{H}_{2} \mathrm{O}$, respectively.

crystallinity remained after the reexpansion treatment, and no evidence of new phases was found. These results are only compatible with a lithium location close to the interlayer space where water molecules can access them.

Structural changes occurring after these experiments were investigated through ${ }^{27} \mathrm{Al}$ and ${ }^{29} \mathrm{Si}$ MAS NMR spectrosopy. The greater degree of tetrahedral substitution of the Trancos sample provided direct evidence on the lithium migration mechanism. Fig. 2 shows ${ }^{29} \mathrm{Si}$ and ${ }^{27} \mathrm{Al}$ MAS NMR spectra for this sample at different stages of the study.

The ${ }^{29} \mathrm{Si}$ spectrum of the initial sample shows a single signal, with a slight asymmetry, centred at $\delta-95.6$, attributable to a $\mathrm{Q}^{3}(0 \mathrm{Al})$ environment with a small contribution of $\mathrm{Q}^{3}(1 \mathrm{Al})$ due to the tetrahedral aluminium substitution. ${ }^{10}$ After thermal treatment and subsequent collapse, curve $(b)$, a band shift occurs at a higher field, compatible with neutralization of the layer charge owing to migration of the lithium ions either to the octahedral holes or to the hexagonal cavities in the tetrahedral layers, ${ }^{11}$ which causes distortions of the $\mathrm{Si}-\mathrm{O}-\mathrm{Si}$ angles of the $\mathrm{SiO}_{4}$ tetrahedra. ${ }^{12}$ Changes in the distribution of bond angles cause the increased ${ }^{29} \mathrm{Si}$ peak width. Following the reexpansion treatment, curve $(c)$, the ${ }^{29} \mathrm{Si}$ signal is restored to a value close to that of the initial sample. According to Tennakoon et al.,${ }^{13}$ this could imply abstraction of trapped lithium ions and transference to the interlamellar space.

As regards ${ }^{27} \mathrm{Al}$ spectra, the parent sample exhibits a main resonance band at $\delta 0$ assigned to octahedral aluminium, with its spinning side bands marked with asterisks in Fig. 2, as well as a weaker signal at $\delta 67$ corresponding to tetrahedral aluminium. When heated at $300^{\circ} \mathrm{C}$, curve $(b)$, there is no variation in $\mathrm{Al}^{\mathrm{VI}}$ signal, but the $\mathrm{Al}^{\mathrm{IV}}$ signal disappears. This can be explained by a lack of symmetry of the aluminium tetrahedra, distorted by the proximity of the lithium ions, which strongly increases the quadrupole coupling constant, giving such a broad line that it cannot be observed. ${ }^{14}$ Location of $\mathrm{Li}^{+}$ions in the hexagonal holes in the tetrahedral layers, closest position to $\mathrm{Al}{ }^{\mathrm{IV}}$, is the only possibility to explain this observation. An interpretation based on the $\mathrm{Li}$ migration to octahedral sites is totally ruled out because structural studies have shown the absence of distortions in the lattice when lithium occupies octahedral positions ${ }^{15}$ and because the AlIV MAS NMR signal for a natural sample containing octahedral $\mathrm{Li}$ is not distorted.16 After the reexpansion experiment, a pattern similar to that of the initial sample is obtained, with disappearance of the distorting effects on the symmetry of the $\mathrm{AlO}_{4}$ group, caused by the dehydrated lithium ions located in the hexagonal holes of the tetrahedral layers. 
This conclusion, about the location of migrated lithium ions, explains both the influence they exert on tetrahedral aluminium and their rehydration, since they would be accessible to water molecules under high pressure. The parallel study of two different samples has shown that the reexpansion is irrespective of their charge-deficit distributions, and the use of a more tetrahedrally substituted montmorillonite has made it possible to observe the direct effect of lithium ions on the silicate structure.

We thank DGICYT for financial support (Project No. PB91-0614).

Received, 23rd April 1993; Com. 3/02354K

\section{References}

1 (a) T. J. Pinnavaia, Science, 1983, 220, 365. (b) J. M. Trillo, M. D. Alba, M. A. Castro, A. Muñoz, J. Poyato and M. M. Tobías. Clay Miner., 1992, 27, 423

2 F. González-García, Anal. R. Soc. Esp. Fis Quím., Ser. B, 1949, 45, 1183; U. Hofmann and R. Klemen, Z. Anorg. Chem., 1950, 262, 95; R. Greene-Kelly, Clay Miner. Bull., 1953, $2,52$.
3 R. Calvet and R. Prost, Clays Clay Miner., 1971, 19, 175 .

4 R. Greene-Kelly, Clay Miner. Bull., 1952, 1121.

5 R. Tettenhorst, Am. Mineral., 1962, 47, 769; V. C. Farmer and J. D. Russell, Clays Clay Miner., 1967, 15, 121.

6 W. F. Jaynes and J. M. Bigham, Clays Clay Miner., 1987, 35, 440.

7 (a) V. Luca, C. M. Cardile and R. H. Meinhold, Clay Miner., 1989, 24, 115. (b) J. Williams, J. H. Purnell and J. A. Ballantine, Catal. Lett., 1991, 9, 115.

8 Data Handbook for Clay Materials and other non-metallic Minerals, ed. H. van Olphen and J. J. Fripiat, Pergamon Press, Oxford, 1979.

9 J. M. Trillo, J. Poyato, M. M. Tobías and M. A. Castro, Clay Miner., 1990, 25, 485

10 M. Mägi, E. Lippmaa, A. Samoson, G. Engelhardt and A. R. Grimmer. J. Phys. Chem., 1984, 88, 1518.

11 D. T. B. Tennakoon, J. M. Thomas, W. Jones, T. A. Carpenter and S. Ramdas. J. Chem. Soc., Faraday Trans. I, 1986, 82, 545.

12 G. Engelhardt and R. Radeglia, Chem. Phys. Lett., 1984, 108, 271.

13 D. T. B. Tennakoon, W. Jones and J. M. Thomas, J. Chem. Soc., Faraday Trans. I, 1986, 82, 3081.

14 D. Plee, F. Borg, L. Gatineau and J. J. Fripiat, J. Am. Chem. Soc., 1985, 107, 2362.

15 E. W. Radoslovich, Am. Miner., 1962, 47, 599; 617.

16 D. E. Woessner, Am. Miner., 1989, 74, 203. 